\title{
Exigências de energia para mantença e eficiência de utilização da energia metabolizável para mantença e ganho de peso de caprinos Moxotó ${ }^{1}$
}

\author{
Kaliandra Souza Alves ${ }^{2 *}$, Francisco Fernando Ramos de Carvalho ${ }^{3}$, Antonia Sherlânea \\ Chaves Véras ${ }^{3}$, Ângela Maria Vieira Batista ${ }^{3}$, Geovergue Rodrigues de Medeiros ${ }^{2}$, \\ Valéria Louro Ribeiro ${ }^{4}$, Alessandra Oliveira de Araújo ${ }^{5}$
}

\author{
1 Projeto financiado pelo CNPq. \\ 2 PDIZ (UFRPE/UFPB/UFC)/UDP - UFRA Carajás. \\ ${ }^{3}$ Departamento de Zootecnia/UFRPE (Bolsista de Produtividade em Pesquisa do CNPq). \\ 4 Programa de Pós-graduação (Mestrado em Zootecnia). \\ ${ }^{5}$ Bolsista do PET/UFRPE.
}

RESUMO - Objetivou-se avaliar as exigências líquidas de energia para mantença e as eficiências de utilização da energia metabolizável (EUEM) para mantença $(\mathrm{km})$ e ganho de peso (kf). Utilizaram-se 26 animais da raça Moxotó, machos nãocastrados com peso vivo (PV) médio inicial de $15 \mathrm{~kg}$ e 7 a 8 meses de idade, alimentados com dieta contendo 2,6 Mcal de energia metabolizável. No início do experimento, seis animais foram abatidos e serviram como referência para estimativa da composição corporal e do peso de corpo vazio (PCVZ) iniciais. Posteriormente, os animais foram distribuídos inteiramente ao acaso em grupos homogêneos de quatro animais, um para cada nível de consumo: alimentação à vontade $(\mathrm{AV})$ e alimentação restrita (85, 70 e 55\% do consumido pelo grupo que recebeu alimentação à vontade). No momento em que o PV dos animais que recebiam alimentação à vontade se aproximava de 25 kg, o grupo era abatido. As exigências líquidas de energia para mantença foram estimadas pelas relações logarítmica ou exponencial da produção de calor (PC) e o consumo de energia metabolizável (CEM). As km e kf foram calculadas como a relação entre a energia líquida da dieta para ganho ou mantença e a concentração de energia metabolizável das dietas. Posteriormente, estimaram-se as exigências de EM e NDT. A exigência de energia líquida para mantença, de 55,11 kcal/kgPCVZ ${ }^{0,75}$, foi próxima ao predito pelas normas norteamericanas para essa espécie. Esse valor é considerado baixo se comparado aos reportados na literatura brasileira pesquisada. A km estimada foi de 0,57 e as kf para as concentrações de 2,99; 2,95; 2,56 e 2,5 Mcal/kg de MS foram de 0,22; 0,19; 0,28 e 0,36 , respectivamente.

Palavras-chave: crescimento, metabolismo basal, peso do corpo vazio, requerimento

\section{Energy requirements for maintenance and net efficiency of metabolizable energy utilization for maintenance and weight gain of Moxotó kids}

ABSTRACT - Twenty-six Moxotó non-castrated male kids (averaging $15 \mathrm{~kg}$ of initial live weight (LW) and 6-8 months old) fed a diet with 2.6 Mcal of metabolizable energy were used to predict the net energy requirements for maintenance and net efficiency of metabolizable energy utilization (EMEU) for maintenance (km) and weight gain (kf). At the beginning of the experiment, six animals were slaughtered as reference to estimate initial body composition and initial empty body weight (EBW). Afterwards, five groups of four animals (one for each intake levels) were assigned to a complete randomized design, in the following treatments: $100 \%$ or ad libitum (AL), 85, 70 and 55 of ad libitum. Each group was slaughtered when BW of AL animals reached $25 \mathrm{~kg} \mathrm{LW}$. The net energy requirements for maintenance were estimated by the logarithm or exponential relations of heat production (HP) and metabolizable energy intake. Estimates of $\mathrm{km}$ and $\mathrm{kf}$ were calculated as the relation between dietary net energy for gain and maintenance, respectively, and the dietary ME concentration. After, ME and TDN requirements were estimated. The net energy requirement for maintenance of $55.11 \mathrm{kcal}$ per $\mathrm{kg} \mathrm{EBW}^{0.75}$ was next to the predicted by the North American report for this specie. This value is considered low if compared to that reported in the Brazilian literature. Km estimate was of 0.57 . Kf estimates were of $0.22,0.19,0.28$ and 0.36 , respectively, for the concentrations of 2.99, 2.95, 2.56 e $2.5 \mathrm{Mcal} / \mathrm{kg}$ of DM.

Key Words: growth, basal metabolism, empty body weight, requirement 


\section{Introdução}

A energia é o nutriente mais relevante para o metabolismo animal. Portanto, o não suprimento das necessidades do animal pode alterar negativamente o desempenho animal em todos os estádios fisiológicos. O adequado suprimento de energia é importante para melhorar a produtividade animal.

Embora em muitas situações práticas a mantença seja considerada condição teórica, é necessário avaliar exigências de mantença separadamente das exigências de produção (Resende et al., 2005), uma vez que o conhecimento dessas exigências é fundamental para determinação das necessidades energéticas totais dos animais. De acordo com Ferrell \& Jenkins (1985), a energia metabolizável (EM) necessária para produção de carne 65 a 70\% são utilizados para atender aos requerimentos de mantença. Contudo, estes requerimentos dependem do peso, da idade, da condição sexual, do nível de produção, da raça, da espécie, das atividades, do nível nutricional, da nutrição prévia, do estresse, das condições ambientais e do exercício (NRC, 1981; Véras et al., 2000; Resende et al., 2005).

A exigência de energia para mantença em caprinos não tem sido muito bem definida. Ainda hoje essas informações para caprinos nativos são escassas, especialmente para a raça Moxotó. Segundo Luo et al. (2004a), vários estudos sobre metabolismo energético têm sido conduzidos com caprinos, mas houve variação nas estimativas de energia líquida para mantença (ELm) e energia metabolizável $\left(\mathrm{EM}_{\mathrm{m}}\right)$.

Os comitês internacionais (NRC, 1981; AFRC, 1998), em virtude do reduzido número de dados disponíveis na ocasião de suas publicações, recomendam valores únicos, independentemente do genótipo. No Brasil, na última década, foram realizadas pesquisas utilizando principalmente raças leiteiras, como a Saanen e seus mestiços (Teixeira, 2004).

Recentemente, um grupo de pesquisadores da E (Kika) de la Garza Institute for Goat Research, Langston Universit propôs a separação das exigências para mantença de quatro grandes grupos raciais: animais especializados para produção de carne (mais que $50 \%$ da raça Boer), nativos, leiteiros e Angorá e preconizaram como exigência de mantença valores de 117, 117, 139 e 134 kcal EM/ $/ \mathrm{kg}^{0,75}$, respectivamente (Sahlu et al., 2004).

Luo et al. (2004a) determinaram a ELm como $71,22 \mathrm{kcal} / \mathrm{kg} \mathrm{PV}^{0,75}$ e, considerando a eficiência de utilização de 0,691, estimaram a EMm como 103,07 kcal/kg PV ${ }^{0,75}$.

O NRC (1981) recomenda valor médio de 101,38 kcal $\mathrm{EM} / \mathrm{kg} \mathrm{PV}^{0,75}$ como exigência de mantença, embora esse valor resulte da média de poucos trabalhos experimentais com animais de composição genética diferente, em comparação aos realizados com raças nacionais, sobretudo as nordestinas. A partir desse valor, o NRC (1981) considera o nível de atividade muscular e acrescenta $25 \%$ para animais submetidos à baixa atividade (manejo intensivo, pastejo em boas pastagens tropicais); 50\% para média atividade (condições de semi-árido e pastagens com pouca inclinação) e 75\% para alta atividade (condições áridas ou montanha e vegetação escassa).

Em virtude da necessidade de obtenção de dados sobre exigências nutricionais de caprinos para elaboração de tabelas com base nas condições brasileiras, objetivou-se com este trabalho estimar as exigências em energia para mantença e a eficiência de utilização da energia metabolizável para mantença em caprinos da raça Moxotó com 15 a 25 kg de peso vivo.

\section{Material e Métodos}

O experimento foi conduzido no Setor de Caprinocultura do Departamento de Zootecnia da Universidade Federal Rural do Pernambuco, Recife, PE.

Foram utilizados 26 animais machos da raça Moxotó, não-castrados e com 7 a 8 meses de idade, identificados, tratados contra ecto e endoparasitas e alojados individualmente em baias de $1,0 \mathrm{~m} \times 2,80 \mathrm{~m}$, confeccionadas em alvenaria e chão batido, providas de comedouros e bebedouros. Os animais receberam uma dieta contendo 2,6 Mcal de energia metabolizável (EM) durante aproximadamente 30 dias, que compreendeu o período de adaptação. Quando os animais atingiram $15 \mathrm{~kg}$ de PV, deu-se início ao período experimental.

Inicialmente, seis animais foram abatidos e serviram como referência no estudo da composição corporal e do peso de corpo vazio (PCVZ) iniciais. Em seguida, formaram-se cinco grupos de quatro animais, distribuídos ao acaso em quatro tratamentos (níveis de consumo): alimentação à vontade (AV); e alimentação restrita (AR) a 85, 70 e $55 \%$ do consumido pelo grupo com AV. Durante essa fase, realizou-se ajuste de $20 \%$ das sobras apenas para os animais que receberam $\mathrm{AV}$.

A ração fornecida (Tabela 1) para todos os animais foi constituída de $40 \%$ de volumoso (feno de capim-tifton-85, Cynodon dactylon, moído em máquina forrageira com peneira de crivo de $4 \mathrm{~mm}$ ) e $60 \%$ de concentrado, à base de milho, farelo de soja, farelo de trigo, óleo vegetal, calcário e suplemento mineral.

A ração foi formulada para atender aos requerimentos de ganhos de peso médios diários de 150 g/animal/dia, segundo o NRC (1981). O fornecimento das rações experi- 
Tabela 1 - Composição percentual e química da ração

\begin{tabular}{|c|c|}
\hline Ingrediente & $\%$ na MS \\
\hline Feno de capim-tifton & 40,0 \\
\hline Grão de milho moído & 22,1 \\
\hline Farelo de soja & 18,4 \\
\hline Farelo de trigo & 14,9 \\
\hline Óleo vegetal & 2,0 \\
\hline Cálcario calcítico & 1,6 \\
\hline Sal mineral comercial & 1,0 \\
\hline \multicolumn{2}{|l|}{ Composição da ração } \\
\hline Matéria seca \% & 94,0 \\
\hline Proteína bruta 1 & 19,5 \\
\hline Extrato etéreo ${ }^{1}$ & 4,8 \\
\hline Fibra em detergente neutro ${ }^{1}$ & 46,2 \\
\hline Fibra em detergente ácido ${ }^{1}$ & 22,1 \\
\hline Matéria orgânica ${ }^{1}$ & 92,4 \\
\hline Carboidratos totais ${ }^{1}$ & 68,0 \\
\hline Carboidratos não-fibrosos ${ }^{1}$ & 24,9 \\
\hline Matéria mineral ${ }^{1}$ & 7,6 \\
\hline Energia metabolizável, Mcal/kg de $\mathrm{MS}^{2}$ & 2,6 \\
\hline $\mathrm{Ca}^{1,3}$ & 0,9 \\
\hline $\mathrm{P}^{1,3}$ & 0,4 \\
\hline
\end{tabular}

$1 \%$ na MS.

2 Obtida a partir da estimativa do NDT (NRC, 2001) e pelas relações: $1 \mathrm{~kg}$ de NDT $=4,409 \mathrm{Mcal}$ ED e EM $=81,7 \% \mathrm{ED}$.

${ }^{3}$ Estimado segundo Valadares Filho et al. (2002).

mentais foi realizado às 8 e $15 \mathrm{~h}$, conforme os tratamentos pré-estabelecidos, com água à disposição dos animais.

Os animais pertencentes aos quatro grupos de alimentação foram pesados no início do experimento, ao final do período de adaptação e a cada 28 dias durante o período experimental. Realizaram-se pesagens intermediárias quando o PV dos animais com AV se aproximou do peso determinado para abate, de $25 \mathrm{~kg}$, ou seja, entre 11 e 12 meses de idade.

Decorridos 60 dias da entrada do grupo no experimento, utilizando-se o mesmo ensaio de desempenho, conduziu-se um ensaio de digestibilidade e metabolismo visando estimar os coeficientes de digestibilidade aparente da ração experimental.

Antes da alimentação da manhã, coletaram-se alimentos e sobras de cada unidade experimental, que, depois de pesadas, registradas e amostradas, foram identificadas e armazenadas diariamente para formação de uma amostra composta ao final do período do ensaio de digestibilidade, que compreendeu três dias alternados.

Durante o período do ensaio de digestibilidade, também foram coletadas e pesadas as fezes excretadas para determinação da produção de matéria seca fecal (PMSF), sendo, em seguida, amostradas, identificadas e armazenadas a $-15^{\circ} \mathrm{C}$. Posteriormente, todas as amostras foram pré-secas em estufa ventilada a $65^{\circ} \mathrm{C}$ e misturadas, para constituir uma amostra composta, que foi homogeneizada retirando-se uma alíquota representativa, a qual foi processada em moinho com peneira de crivo de $1 \mathrm{~mm}$. O período de adaptação para este ensaio correspondeu àquele que os animais permaneceram no ensaio de desempenho

Para estimativa da PMSF, utilizou-se a fibra em detergente ácido indigestível (FDAI) como indicador. Amostras de fezes, alimentos e sobras foram incubadas no rúmen de um búfalo macho, adulto, mestiço, castrado, por um período de 144 horas, em sacos tipo ANKON, segundo metodologia descrita por Berchielli et al. (2000), exceto quanto à incubação, que foi in situ. A quantidade da amostra incubada foi de $1,0 \mathrm{~g}$ para alimentos concentrados e $0,5 \mathrm{~g}$ para feno, fezes e sobras. O material remanescente da incubação foi submetido à extração com detergente ácido, cujo resíduo foi considerado FDAI.

As determinações de MS, MO, MM, nitrogênio total (N), EE e FDA foram realizadas conforme técnicas descritas por Silva \& Queiroz (2002). O teor de proteína bruta (PB) foi obtido pelo produto entre o teor de $\mathrm{N}$ e o fator 6,25; e o de fibra em detergente neutro (FDN), de acordo com metodologia descrita por Van Soest et al. (1991).

Os carboidratos totais (CT), assim como o consumo de nutrientes digestíveis totais, foi obtido conforme recomendações de Sniffen et al. (1992); e os CNF, segundo Mertens (1997). Os teores de NDT, em porcentagem, foram obtidos por meio da relação entre o consumo de NDT e consumo de MS. A energia digestível (ED) foi calculada como o produto entre o teor de NDT e o fator 4,409 e a concentração de EM foi considerada 82\% da ED (Sniffen et al., 1992). Os consumos de ED e EM foram obtidos a partir do consumo de NDT.

Antes do abate, os animais foram pesados para obtenção do PV. Depois, foram submetidos a um jejum de alimentos sólidos por 18 horas e novamente pesados para obtenção do PV ao abate (PVA). Após o abate, o animal foi eviscerado e o conteúdo do trato gastrintestinal foi retirado para determinação do PCVZ. Posteriormente, a metade do corpo vazio do animal (que compreendia de forma proporcional e homogênea: carcaça, todos os órgãos, patas, cabeça, pele e sangue recolhido no momento da sangria) foi pesada e congelada, cortada em serra de fita, moída e homogeneizada, momento em que foram retiradas amostras de aproximadamente 250 g por animal e, em seguida, submetidas à desidratação em estufa de $105^{\circ} \mathrm{C}$, por um período médio de 72 horas, para determinação do teor de matéria seca gordurosa (MSG). As amostras foram desengorduradas, por lavagens sucessivas com éter de petróleo, obtendo-se a matéria seca prédesengordurada (MSPD).

Seqüencialmente, as amostras foram processadas em moinho de bola e acondicionadas em potes plásticos para posteriores análises de gordura, $\mathrm{N}$ total, MM e MS para 
eventuais correções de umidade, conforme descrito por Silva \& Queiroz (2002).

Considerando a diferença entre a MSG e a MSPD, calculou-se a gordura removida no pré-desengorduramento, a qual foi adicionada aos resultados obtidos na determinação do extrato etéreo ainda contido na MSPD. A partir do conhecimento dos teores de proteína e gordura na MSPD e o peso da amostra submetida ao pré-desengorduramento, determinaram-se os teores na matéria natural, totalizando $100 \%$ do PCVZ.

Os conteúdos corporais de gordura (CCG), proteína (CCP) e energia (CCE) foram determinados em relação às suas concentrações percentuais no corpo dos animais. A estimativa do CCE foi realizada conforme a equação: CCE Mcal = 5,6405 (CCP kg) +9,3929 (CCG kg), preconizada pelo ARC (1980).

As exigências líquidas de energia para mantença (ELm), ou seja, a produção de calor (PC) em jejum, foram estimadas por meio da equação de regressão linear entre o logaritmo (log) da PC e o consumo de energia metabolizável (CEM), expressas em $\mathrm{kcal} / \mathrm{kg}^{0,75} / \mathrm{dia}$. Extrapolando a referida equação para o nível zero de consumo de EM, obteve-se a ELm como o anti-log da intercepta da equação obtida, segundo metodologia descrita por Lofgreen \& Garrett (1968). A ELm também foi predita pelo coeficiente da equação de regressão não-linear entre a produção de calor e o consumo de EM, conforme descrito por Ferrell \& Jenkins (1998 a,b), dos animais de todos os tratamentos, inclusive os que recebiam 100\%. A equação é descrita da seguinte forma:

$$
\mathrm{Y}=\mathrm{A}\left(1-\mathrm{B}^{*} \exp (\mathrm{C}(\mathrm{X}-\mathrm{D}))\right)
$$

em que: $\mathrm{Y}=$ energia retida; $\mathrm{A}, \mathrm{B}$ e $\mathrm{C}=$ coeficientes de regressão; $\mathrm{D}$ = estimativa da produção de calor em jejum; e $\mathrm{X}$ = consumo de energia metabolizável.

As quantidades de energia líquida das dietas foram calculadas conforme descrito por Harris (1970).

O consumo de matéria seca suficiente para manter o equilíbrio de energia foi calculado dividindo-se o consumo de EM necessário para mantença, pela concentração de EM (kcal/kg de MS) da dieta em cada nível de alimentação. O consumo de EM necessário para a mantença foi obtido por processo iterativo utilizando-se a equação de regressão entre log da produção de calor e o consumo de EM, expresso em kcal $/ \mathrm{kg}^{0,75} /$ dia.

A energia líquida para mantença de cada nível de alimentação (ELmd) foi obtida dividindo-se a produção de calor em jejum ( $\mathrm{kcal} / \mathrm{kgPCVZ}^{0,75}$ ) pelo consumo de MS para manter o equilíbrio de energia, expresso em g de MS $/ \mathrm{kg}^{0,75}$; enquanto o consumo de MS superior às necessidades de mantença foi obtido subtraindo-se do consumo total de MS (g/MS/ $/ g^{0,75}$ ) o consumo de MS suficiente para o equilíbrio de energia (g/MS/ $\mathrm{kg}^{0,75}$ ), para cada dieta. A concentração de energia líquida para ganho de cada dieta (ELgd) foi calculada dividindo-se a energia retida diariamente, em $\mathrm{kcal} / \mathrm{kg}^{0,75}$, pelo consumo de MS acima das necessidades de mantença, expresso em g MS/ $\mathrm{kg}^{0,75}$.

Para predição das estimativas das exigências de energia metabolizável para mantença e ganho a partir das exigências líquidas, calcularam-se as eficiências de utilização da energia metabolizável para mantença $(\mathrm{km})$ e ganho de peso (kf) dividindo-se as ELmd e ELgd pela concentração de EM da dieta.

Os requisitos de EM para mantença e ganho foram obtidos pelas relações entre as exigências líquidas preditas neste trabalho e as respectivas eficiências de utilização da energia metabolizável, estimadas segundo Harris (1970). As exigências de NDT foram calculadas dividindo-se as exigências de EM por 0,82, obtendo-se as exigências de energia digestível (ED) e, posteriormente, dividindo-se as exigências de ED por 4,409.

Para predição do PCVZ a partir do PV, foi utilizada equação obtida para predição do PCVZ em diferentes intervalos de peso, considerando o $\mathrm{PV}$, ajustada para todos os dados: $\mathrm{PCVZ}=-1.2212+0,9132 \mathrm{PV}, \mathrm{r}^{2}=0,98$.

\section{Resultados e Discussão}

O consumo de MS diminuiu com a restrição alimentar, o que era esperado (Tabela 2), no entanto, a digestibilidade aparente da MS (DAMS) foi menor nos animais submetidos a maior restrição, o que não era esperado, pelo fato de o nível de consumo mais baixo favorecer a digestibilidade dos alimentos, em virtude do maior tempo de permanência do alimento no rúmen, que diminui, conseqüentemente, a taxa de passagem, melhorando seu aproveitamento pelos microrganismos ruminais e pelo animal. A maior disponibilidade de alimentos para os animais com alimentação à vontade, com $20 \%$ de sobras, e $85 \%$ do consumo à vontade, permitiu maior seletividade, característica peculiar da espécie caprina, e favoreceu a digestibilidade nesses dois níveis de alimentação.

Diferentemente dos nutrientes PB e EE, os CT e FDN efetivamente consumidos foram positivamente influenciados pela restrição alimentar, o que permite inferir que este comportamento resultou em menor digestibilidade dos alimentos nos animais submetidos à maior restrição alimentar (Tabela 2). Como resultado do consumo e da digestibilidade de MS, os EM e a EM da dieta apresentaram o mesmo comportamento.

Os animais alimentados à vontade (AV) apresentaram ganho de peso de aproximadamente $78 \mathrm{~g} /$ dia, valor mais 
Tabela 2 - Consumo de MS, coeficiente de digestibilidade aparente da MS (CDAMS) e energia metabolizável (EM) das dietas experimentais, consumo de EM (CEM) da dieta, porcentagem de nutrientes na dieta efetivamente consumida (DEC) e ganho médio de peso diário (GMPD)

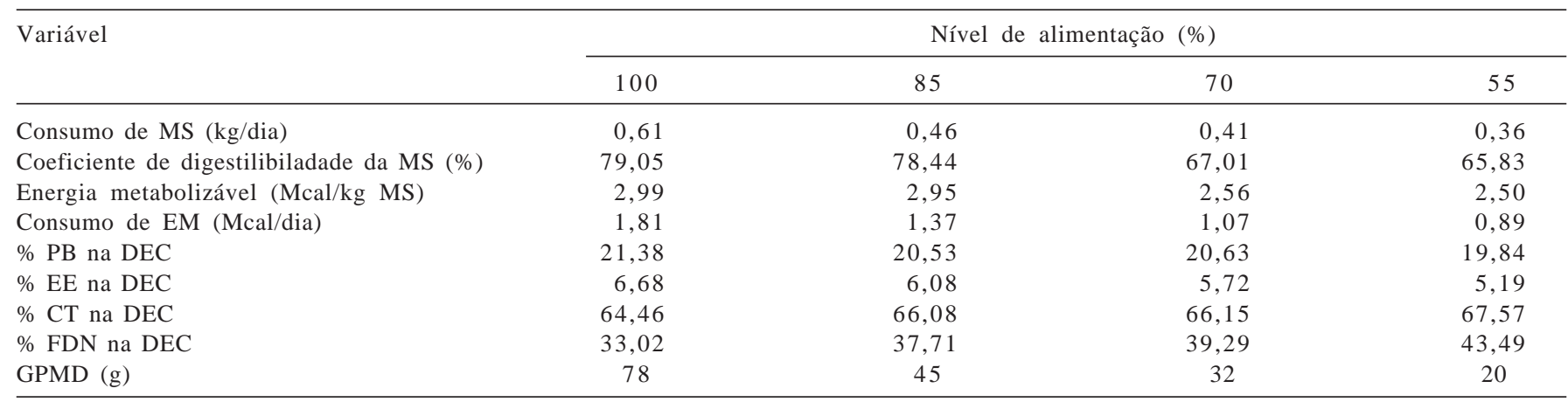

baixo que o esperado, provavelmente resultado do baixo consumo de MS. Os animais ingeriram aproximadamente 2,9\% do PV em MS e essa estimativa foi de 4,25\% do PV, seguindo as recomendações do NRC (1981) para ganho de 150 g/dia. Além disso, os animais com alimentação à vontade consumiram dieta com 33,02\% de FDN, percentual ainda mais elevado para maiores ganhos.

Esse comportamento pode ser atribuído ao fato de os animais Moxotó não serem normalmente criados em regime de confinamento, uma vez que o ambiente é um fator limitante do consumo. Além disso, possivelmente o potencial genético não permitiu ganhos muito elevados e esses animais apresentavam características de início da puberdade, por não terem sido castrados, o que também pode ter influenciado o consumo de MS pelos animais do grupo à vontade e, conseqüentemente, o dos outros grupos.

Com a regressão do logaritmo da produção de calor (PC), em relação ao consumo de energia metabolizável (CEM), em kcal $/ \mathrm{kg}^{0,75} /$ dia, foi obtida a equação Log PC = $1,7413+0,0025$ CEM, $\mathrm{r}^{2}=0,95$ (Figura 1).

Ao extrapolar para o nível zero de CEM, obteve-se um valor relativo de PC do animal em jejum, como o antilog da intercepta, de 55,11 kcal/PCVZ ${ }^{0,75} /$ dia, definido como exigência de energia líquida de mantença (ELm) dos animais. A partir desta equação, obteve-se o consumo de EM no equilíbrio, ou seja, o ponto no qual a produção de calor foi igual ao consumo de EM, de $96 \mathrm{kcal} / \mathrm{kg}^{0,75} /$ dia.

Animais criados em regiões áridas e semi-áridas desenvolvem mecanismo de baixo metabolismo basal e, conseqüentemente, menor produção de calor, com o intuito de manter a temperatura corporal próxima à zona de neutralidade (Sllanikove, 2006). Segundo esse autor, raças de caprinos criadas no deserto apresentam exigências de ELm menores que as demais, comportamento similar ao observado para a raça Moxotó.
As exigências de energia para mantença estimadas neste estudo foram menores que as reportadas pelo Medeiros (2001), Ferreira (2003) e Teixeira (2004).

Os tecidos viscerais, embora em menor proporção no corpo dos animais, são de considerável relevância para os requisitos energéticos de mantença, pois consomem $50 \%$ do total desta energia na síntese de proteína, nos batimentos cardíacos e na produção de calor (Catton \& Dhuyvetter, 1997; Sllanikove, 2006). É provável que a menor exigência de energia para mantença encontrada nesse estudo esteja relacionada à diferença na proporção dos órgãos internos, que utilizam mais os nutrientes por participarem ativamente no metabolismo.

Na predição da ELmd, calcularam-se o consumo de EM necessário para mantença por meio de processo iterativo, que foi de $96 \mathrm{kcal} / \mathrm{kg}^{0,75}$, e o consumo de MS necessário ao equilíbrio de energia (Tabela 3 ).

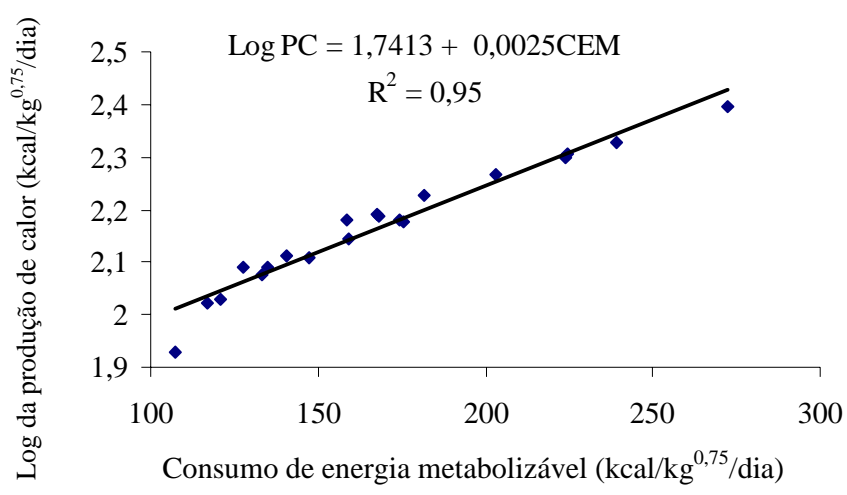

Figura 1 - Logaritmo da produção de calor (kcal/kg ${ }^{0,75}$ PCVZ), em relação ao consumo de energia metabolizável CEM (kcal/ $\left.\mathrm{kg}^{0,75} \mathrm{PCVZ} / \mathrm{dia}\right)$ para caprinos Moxotó. 
O valor de $57 \%$ da $\mathrm{km}$ encontrada utilizando-se os dados experimentais foi $24,56 \%$ inferior ao valor de $71 \%$, estimado por meio da equação proposta por Blaxter (1962) e adotada pelo AFRC (1998) para dietas com 2,6 Mcal de EM.

Pfeffer \& Rodehutscord (1998) encontraram eficiência de utilização da energia metabolizável para mantença de 0,22 para cabritos Saanen pesando $15 \mathrm{~kg}$ PV. A eficiência de utilização da energia predita nesta pesquisa foi $38 \%$ superior à observada por esses autores, embora tenham utilizado nas dietas leite e concentrado de qualidade.

As exigências de Elm, EM, ED e NDT para mantença, para diferentes PV e PCVZ aumentaram, à medida que o peso corporal se elevou (Tabela 4). Para converter as exigências para ganho em PCVZ em exigências para ganho de PV, utilizou-se a equação encontrada, $P C V Z=-1,7778+0,9352$ PV, entre a relação PV e PCVZ dos animais pertencentes aos grupos com AV e alimentação restrita ao nível de 85\%.

Considerando a km obtida de $57 \%$ dos dados experimentais, conforme Harris (1970), e ovalor de 55,11 kcal $/ \mathrm{kgPCVZ}^{0,75}$ como requisito líquido de energia para mantença, os requerimentos de EM seriam de 96,68 kcal/PCVZ ${ }^{0,75}$; os de ED, $117,91 \mathrm{kcal} / \mathrm{PCVZ}^{0,75}$; e os de NDT, 26,74 g/PCVZ ${ }^{0,75}$.

Tabela 3 - Teores de NDT, concentrações de energia metabolizável (EM), energia líquida para mantença (ELmd), energia líquida para ganho (ELgd) de cada dieta e eficiência de utilização da energia metabolizável (EUEM) para mantença $(\mathrm{km})$ e ganho de peso $(\mathrm{kf})$ em relação aos níveis de alimentação (NA)

\begin{tabular}{lcccccccc}
\hline \multirow{2}{*}{ NA (\%) } & \multirow{2}{*}{ NDT (\%) } & \multicolumn{3}{c}{ Mcal/kg de MS } & & \multicolumn{2}{c}{ EUEM (\%) } \\
\cline { 3 - 4 } \cline { 8 - 9 } & & EM & Elmd & ELgd & & km & kf \\
\hline 100 & 71,80 & 2,99 & 1,71 & 0,67 & & 57 & 0,22 \\
85 & 69,69 & 2,95 & 1,69 & 0,55 & & 57 & 0,19 \\
70 & 65,08 & 2,56 & 1,46 & 0,72 & & 57 & 0,28 \\
55 & 58,42 & 2,50 & 1,43 & 0,89 & & 57 & 0,36 \\
\hline
\end{tabular}

As estimativas dos requerimentos de EM para ganho de peso vivo (GPV) (Mcal/kg GPV) e de NDT, em g/kg de GPV, utilizando-se a relação entre os requisitos líquidos estimados para ganho em peso (Tabela 5), pelas kf para as respectivas concentrações de EM das dietas experimentais (Mcal/kg de MS) foram feitas com base nos resultados obtidos por Alves (2006). Neste caso foram utilizados os valores do grupo com $\mathrm{AV}$, uma vez que a estimativa foi relativa às exigências líquidas de energia para ganho de peso.

As exigências de EM aumentaram de acordo com o peso corporal, o que confirma dados do AFRC (1998), que estimou aumento nos requerimentos de EM para ganho médio de $100 \mathrm{~g}$ de 1,4 a 1,7 Mcal/dia com a elevação do peso corporal de 15 para $20 \mathrm{~kg}$, respectivamente, considerando 2,6 como EM da dieta.

Os valores de EM para ganhos obtidos nesta pesquisa foram superiores aos encontrados por Medeiros (2001), Ferreira (2003) e Teixeira (2004), possivelmente pelo fato de a concentração de gordura e a energia depositada no corpo dos animais experimentais terem sido superiores às observadas por esses autores.

\begin{tabular}{lccccc}
$\begin{array}{r}\text { Tabela 4 } \\
\text { - Exigências diárias de energia metabolizável (EMm) e } \\
\text { energia digestível (EDm), expressas em Mcal/dia, e de } \\
\text { NDTm (g/dia) para mantença de caprinos Moxotó }\end{array}$ \\
\hline PV & PCVZ & $\begin{array}{c}\text { Elm } \\
\text { (Mcal) }\end{array}$ & $\begin{array}{c}\text { EMm } \\
\text { (Mcal) }\end{array}$ & $\begin{array}{c}\text { EDm } \\
\text { (Mcal) }\end{array}$ & $\begin{array}{c}\text { NDTm } \\
\text { (g) }\end{array}$ \\
\hline 15 & 12,25 & 0,36 & 0,63 & 0,77 & 175 \\
17,5 & 14,59 & 0,41 & 0,72 & 0,88 & 199 \\
20 & 16,93 & 0,46 & 0,80 & 0,98 & 222 \\
22,5 & 19,26 & 0,51 & 0,88 & 1,08 & 245 \\
25 & 21,60 & 0,55 & 0,96 & 1,18 & 267 \\
\hline
\end{tabular}

A eficiência de utilização da energia metabolizável (EUEM) foi obtida conforme Harris (1970)

PCVZ = peso de corpo vazio

Tabela 5 - Estimativa dos requisitos de energia líquida para ganho de peso (ELg), em Mcal/100 g de ganho de peso vivo (GPV), de EM, em Mcal/100 g GPV, obtidas considerando as concentrações de EM das dietas (Mcal/kg de MS) e as respectivas eficiências de utilização da energia metabolizável para ganho de peso (kf), em \%, de caprinos Moxotó

\begin{tabular}{|c|c|c|c|c|c|c|}
\hline \multirow[t]{4}{*}{ PV (kg) } & \multirow[t]{4}{*}{ PVCZ (kg) } & & \multicolumn{4}{|c|}{ Nível de alimentação (\%) } \\
\hline & & \multirow{4}{*}{ Elg (Mcal/100 g GPV) } & 100 & 85 & 70 & 55 \\
\hline & & & \multicolumn{4}{|c|}{ EM da dieta - Mcal/kg de MS (Kf) } \\
\hline & & & $2,99(0,22)$ & $2,95(0,19)$ & $2,56(0,28)$ & $2,5(0,36)$ \\
\hline & & & \multicolumn{4}{|c|}{ Exigências EM } \\
\hline 15,00 & 12,48 & 0,259 & 1,16 & 1,39 & 0,93 & 0,73 \\
\hline 17,50 & 14,76 & 0,277 & 1,24 & 1,48 & 0,99 & 0,77 \\
\hline 20,00 & 17,04 & 0,292 & 1,31 & 1,56 & 1,04 & 0,82 \\
\hline 22,50 & 19,33 & 0,306 & 1,37 & 1,64 & 1,09 & 0,86 \\
\hline 25,00 & 21,61 & 0,319 & 1,43 & 1,71 & 1,14 & 0,89 \\
\hline
\end{tabular}


Verifica-se que, quanto maior a EUEM, menor a ELg. Os animais que receberam AR no nível de 55\%, ainda assim, conseguiram manter ganho de 20 g (Tabela 2). Portanto, esse grupo apresenta menor ELg que os outros níveis de alimentação.

\section{Conclusões}

A exigência de energia para mantença de caprinos Moxotó entre 15 e $25 \mathrm{~kg}$ de peso vivo éde 55,11 kcal/PCVZ ${ }^{0,75}$. A eficiência de utilização da energia metabolizável para mantença foi de $57 \%$ e a eficiência de utilização dessa energia para ganho de peso, de 0,22; 0,19; 0,28 e 0,36\% para as dietas com 2,99; 2,95; 2,56 e 2,5 Mcal de energia metabolizável/kg de matéria seca, respectivamente.

\section{Agradecimento}

Ao CNPq, pelo fomento dispensado a esta pesquisa, à Universidade Federal Rural de Pernambuco - UFRPE e ao Programa de Doutorado Integrado em Zootecnia - PDIZ (UFRPE-UFPB-UFC) do Departamento de Zootecnia da UFRPE, pelo apoio para a realização deste trabalho. Aos alunos de graduação que contribuíram na execução desta pesquisa.

À Universidade Federal Rural da Amazônia, por liberar-me das atividades acadêmicas para concluir o curso de Doutorado.

\section{Literatura Citada}

AGRICULTURAL AND FOOD RESEARCH COUNCIL - AFRC. The nutrition of goats. Aberdeen: Technical Committee on Responses to Nutrients. 1998. v.67, 170p. (Report, 10).

AGRICULTURAL RESEARCH COUNCIL - ARC. The nutrient requirements of ruminant livestock. London: 1980. 351p.

ALVES, K.S. Exigências de proteína e energia para caprinos Moxotó em crescimento. Recife: Universidade Federal Rural de Pernambuco, 2006. 83p. Tese (Doutorado em Zootecnia) Universidade Federal Rural de Pernambuco, 2006.

ARAÚJO, G.G.L.; VALADARES FILHO, S.C.; SILVA, J.F.C. et al. Eficiência de utilização da energia metabolizável, para mantença e ganho de peso, e exigências de energia metabolizável e nutrientes digestíveis totais de bezerros alimentados com dietas contendo diferentes níveis de volumoso. Revista Brasileira de Zootecnia, v.27, n.5, p.1031-1036, 1998.

BERCHIELLI, T.T.; ANDRADE, P.; FURLAN, C.L. Avaliação de indicadores internos em ensaios de digestibilidade. Revista Brasileira de Zootecnia, v.29, n.3, p.830-833, 2000.

CATTON, J.S.; DHUYVETTER, D.V. Influence of energy supplementation on grazing ruminants: requirements and responses. Journal of Animal Science, v.75, p.533-542, 1997.

COELHO DA SILVA, J.F.; LEÃO, M.I. Fundamentos de nutrição dos ruminantes. Piracicaba: Livroceres, 1979. 380p.

FERREIRA, A.C.D. Composição corporal e exigências nutricionais em proteína, energia e macrominerais de caprinos Saanen em crescimento. Jaboticabal: Universidade
Estadual Paulista, 2003. 86p. Tese (Doutorado em Zootecnia) - Universidade Estadual Paulista, 2003.

FERRELL, C.L.; JENKINS, T.G. Body composition and energy utilization by steers of diverse genotypes fed a high-concentrate diet during the finishing period: I. Angus, Belgian Blue, Hereford, and Piedmontese sires. Journal of Animal Science, v.76, p.637-646, 1998a.

FERRELL, C.L.; JENKINS, T.G. Body composition and energy utilization by steers of diverse genotypes fed a high-concentrate diet during the finishing period: II. Angus, Boran, Brahman, Hereford, and Tuli sires. Journal of Animal Science, v.76, p.647-657, 1998b.

FERRELL, C.L.; JENKINS, T.G. Cow type and the nutritional environment: nutritional aspects. Journal of Animal Science, v.61, n.3, p.725-741, 1985.

GARRETT, W.N. Factors influencing energetic efficiency of beef production. Journal of Animal Science, v.51, n.6, p.14341440, 1980.

GEAY, Y. Energy and protein utilization in growing cattle. Journal of Animal Science, v.58 n.3, p.766-778, 1984.

HARRIS, L.F. Nutrition research techniques for domestics and wild animals. Utah: Logan, v.1. 1970.

LOFGREEN, G.P.; GARRET, W.N. A system for expressing net energy requirements and feed values for growing and finishing beef cattle. Journal of Animal Science, v.27, n.3, p.793-806, 1968.

LU, C.D.; SAHLU, T.; FERNANDEZ, J.M. Assessment of energy and protein requirements for growth and lactation in goats. In: INTERNATIONAL CONFERENCE ON GOATS, 4., 1987, Brasília. Proceedings... Brasília, EMBRAPA, 1987. p.1229-1247.

LUO, J.; GOETSCH, A.L.; NSAHLAI, I.V. et al. Maintenance energy needs of goats: predictions based on observations of heat and recovered energy. Small Ruminant Research, v.53, p.221230, 2004a.

LUO, J.; GOETSCH, A.L.; NSAHLAI, I.V. et al. Prediction of metabolizable energy and protein requirement for maintenance, gain and fiber growth of Angora goats. Small Ruminant Research, v.53, p.339-356, 2004b.

MEDEIROS, A.N. Estimativa da composição corporal e exigências em proteína e energia para caprinos Saanen na fase inicial de crescimento. Jaboticabal: Universidade Estadual Paulista, 2001. 106p. Tese (Doutorado em Zootecnia) - Universidade Estadual Paulista, 2001.

MERTENS, D.R. Creating a system for meeting the fiber requirements of dairy cows. Journal of Dairy Science, v.80, n.7, p.1463-1481, 1997.

NATIONAL RESEARCH COUNCIL - NRC. Nutrients requirements of beef cattle. 7. ed. rev. Washington, D.C.: National Academy Press, 2000. 232p.

NATIONAL RESEARCH COUNCIL - NRC. Nutrient requirements of goats: Angora, dairy, and meat goats in temperate and tropical countries. Washington, D.C.: National Academy Press, 1981. p.26-48.

OWENS, F.N.; DUBESKI, P.; HANSON, C.F. Factors that alter the growth and development of ruminants. Journal of Animal Science, v.71, p.3152-3172, 1993.

OWENS, F.N.; GILL, D.R.; SECRIST, D.S. Review of some aspects of growth and development of feedlot cattle. Journal of Animal Science, v.73, p.3152-3172, 1995.

PFEFFER, E.; RODEHUTSCORD, M. Body chemical composition and utilization of dietary energy by male Saanen kids fed either milk to satiation or solid complete feeds with two proportions of straw. Journal of Agricultural Science, v.131, p.487-495, 1998.

RESENDE, K.T.; FERNANDES, M.H.M.; TEIXEIRA, I.A.M.A. et al. Exigências nutricionais de caprinos e ovinos. In: REUNIÃO ANUAL DA SOCIEDADE BRASILEIRA DE ZOOTECNIA, 42. 2005, Goiânia. Anais... Goiânia: Sociedade Brasileira de Zootecnia, 2005. p.114-135. 
SAHLU, T.; GOETSCH, A.L.; LUO, J. Nutrient requirements of goats: developed equations, other considerations and future research to improve them. Small Ruminant Research, v.53, p.191-219, 2004.

SILVA, D.J.; QUEIROZ, A.C. Análise de alimentos (métodos químicos e biológicos). 3.ed. Viçosa, MG: Universidade Federal de Viçosa, 2002. 235p.

SLLANIKOVE, N. [2006]. Why goats raised on harsh environment perform better than other domesticated animals. Disponível em: < resources. Cimeam.org/om/pdf/a34/ 97606135.pdf > Acesso em: 21/5/2006.

SNIFFEN, C.J.; O' CONNOR, J.D.; Van SOEST, P.J. et al. A net carbohydrate and protein system for evaluating cattle diets: II Carbohydrate and protein availability. Journal of Animal Science, v.70, p.3562-3577, 1992.

TEIXEIRA, I.A.M.A. Métodos de estimativa da composição corporal e exigências nutricionais de cabritos $F 1$ Boer $x$ Saanen. Jaboticabal: Universidade Estadual Paulista, 2004. 93p. Tese (Doutorado em Zootecnia) - Universidade Estadual Paulista, 2004.

VALADARES FILHO, S.C.; ROCHA JR., V.R.; CAPPELLE, E.R. Tabelas de composição de alimentos para bovinos. 1.ed. Viçosa, MG: Universidade Federal de Viçosa, 2002. 297p.
Van SOEST, P.J.; ROBERTSON, J.B.; LEWIS, B.A. Methods for extraction fiber, neutral detergent fiber and nonstarch polysaccarides in relation to animal nutrition. Journal of Dairy Science, v.83, n.1, p.3583-3597, 1991.

VÉRAS, A.S.C. Consumo, digestibilidade, composição corporal e exigências nutricionais de bovinos Nelore alimentados com diferentes níveis de concentrado na ração. Viçosa, MG: Universidade Federal de Viçosa, 1999. 159p. Tese (Doutorado em Zootecnia) - Universidade Federal de Viçosa, 1999.

VÉRAS, A.S.C.; VALADARES FILHO, S.C.; COELHO DA SILVA, J.F. et al. Composição corporal e requisitos energéticos e protéicos de bovinos Nelore, não castrados, alimentados com rações contendo diferentes níveis de concentrado. Revista Brasileira de Zootecnia, v.29, n.6, p.2379-2389, 2000.

VÉRAS, A.S.C.; VALADARES FILHO, S.C.; COELHO DA SILVA, J.F. et al. Eficiência de utilização da energia metabolizável para mantença e ganho de peso e exigências de energia metabolizável e de nutrientes digestíveis totais de bovinos Nelore, nãocastrados. Revista Brasileira de Zootecnia, v.30, n.3, p.904-910, 2001. 